\title{
Stable and metastable mixed crystals in the orientationally disordered state of the $\left[\left(\mathrm{CH}_{3}\right)_{3} \mathrm{CCl}\right]+\left[\left(\mathrm{CH}_{3}\right)_{2} \mathrm{CCl}_{2}\right]$ system
}

\author{
Luis C. Pardo a, María Barrio a, Josep Ll. Tamarit ${ }^{\text {a,* }}$, David O. López a \\ Josep Salud a, Philippe Negrier ${ }^{\mathrm{b}}$, Denise Mondieig ${ }^{\mathrm{b}}$ \\ a Departament de Física i Enginyeria Nuclear, E.T.S.E.I.B. Universitat Politècnica de Catalunya, Diagonal, \\ 64708028 Barcelona, Catalonia, Spain \\ ${ }^{\mathrm{b}}$ Centre de Physique Moléculaire, Optique et Hertzienne UMR 5798 du CNRS Université Bordeaux I 351, cours de la Libération, \\ 33405 Talence Cedex, France
}

\begin{abstract}
Stable and metastable mixed crystals in the orientationally disordered (OD) state of the 2 methyl 2 chloro propane $\left(\left(\mathrm{CH}_{3}\right)_{3} \mathrm{CCl}\right)+2,2$ dichlorop ropane $\left(\left(\mathrm{CH}_{3}\right)_{2} \mathrm{CCl}_{2}\right)$ binary system were characterized from crystallo graphic and thermodynamic points of view. Large concentration domains of stable rhombohedral $(\mathrm{R})$ and metastable face centered cubic (FCC) mixed crystals were found despite the non isomorphism relationship between the stable FCC phase of $\left(\mathrm{CH}_{3}\right)_{3} \mathrm{CCl}$ and the stable $\mathrm{R}$ phase of $\left(\mathrm{CH}_{3}\right)_{2} \mathrm{CCl}_{2}$. In addition, a third OD phase region was observed in the $\left(\mathrm{CH}_{3}\right)_{2} \mathrm{CCl}_{2}$ rich side of the system. It is simple cubic (SC) and metastable with respect to the stable $\mathrm{R}$ phase region. This corresp onds to the binary extension of the R SC stable metastable relationship found for pure $\left(\mathrm{CH}_{3}\right)_{2} \mathrm{CCl}_{2}$.
\end{abstract}

\section{Introduction}

Molecular materials composed of globular or pseudo-globular molecules are capable of forming orientationally disordered (OD) phases in which positional order exists and orientational order has been lost [1]. This mesostate is commonly referred to as plastically crystalline state because crystals are often soft and deform under rather small

\footnotetext{
${ }^{*}$ Corresponding author. Fax: +34 934011839.

E mail address: jose.luis.tamarit@upc.es (J.L. Tamarit).
}

stresses. Among these materials, methylchloromethane compounds, $\left(\mathrm{CH}_{3}\right)_{4-n} \mathrm{CCl}_{n}$, where $n$ varies from 0 to 4 , have stimulated many studies because they are good examples of substances displaying such OD crystals [2 14].

The orientational disorder in the methylchloromethane molecules is related to the symmetry of their shape, which approximates to a regular tetrahedron with vertices so rounded that it can easily jump to either of each one of the energetically equivalent orientations in the high-temperature phases, as if it were a sphere [2]. 
X-ray diffraction [2 9], calorimetric [3 6,10,11], birefringence [12 16] and NMR studies [12 14,17] on methylchloromethane compounds with two or more chlorine atoms $(n=2,3,4)$ revealed that these substances exhibit unusual polymorphic behavior. It has been found that, on cooling, a cubic phase (phase Ia) forms first from the melt, then transforms to a rhombohedral phase (phase Ib), which turns to a low-temperature ordered (LTO) phase on further cooling. Heating back from the LTO phase results in the formation of the rhombohedral phase (Ib) which persists until it melts. However, another melting point, lower than that of phase $\mathrm{Ib}$, is found on heating from phase Ia. This indicates that phase Ia is a metastable phase according to the Ostwald's step rule [18], and that the $\mathrm{Ia} \mathrm{Ib}$ transition might be of monotropic character $[19,20]$.

On the opposite, only one OD phase is found for compounds without $(n=0)$ or with one chlorine atom $(n=1)$.

As it was hypothetized that the similarity in molecular shape and size would cause mixtures of these methylchloromethanes to form solid solutions, a study of a series of two-component systems sharing such compounds has been undertaken [ $\left.\begin{array}{ll}3 & 6\end{array}\right]$ which would be of interest for the analysis of how metastability occurs in the mixed crystals as well as for short-range orientational order studies. The purpose of the present Letter is then to describe both aspects for the 2-methyl-2chloropropane $\left(\left(\mathrm{CH}_{3}\right)_{3} \mathrm{CCl}\right)+2$, 2-dichloro propane $\left(\left(\mathrm{CH}_{3}\right)_{2} \mathrm{CCl}_{2}\right)$ two-component system through the construction of the melting phase diagram.

$\left(\mathrm{CH}_{3}\right)_{3} \mathrm{CCl}$ has been largely studied by means of calorimetry, diffraction and spectroscopic techniques $[9,10,21]$. At ordinary pressure it displays three solid phases. The LTO phase (III) is monoclinic $\left(\mathrm{P} 2_{1} / \mathrm{m}\right)$ and transforms at $183.6 \mathrm{~K}$ to a tetragonal $\mathrm{P} 4 / \mathrm{nmm}$ librational phase (II), in which molecules reorient uniaxially about the $\mathrm{C} \mathrm{Cl}$ axis. On further heating, an OD FCC phase appears at $219.6 \mathrm{~K}$ and remains stable up the melting point at $248.1 \mathrm{~K}$. All these transitions revert on cooling.

$\left(\mathrm{CH}_{3}\right)_{2} \mathrm{CCl}_{2}$ exhibits a solid solid transition at $187.8 \mathrm{~K}$ from a LTO monoclinic $(\mathrm{C} 2 / \mathrm{c})$ phase to an OD R stable phase that melts at $236.6 \mathrm{~K}$ $[4,7,11,22]$. The OD phase obtained on cooling from the melt was recently found to be simple cubic (SC) $[4,22]$ instead of FCC, as reported previously [23]. This SC phase is metastable since its melting point at $230.4 \mathrm{~K}$ is lower than that of the $\mathrm{R}$ phase, and the R SC transition in the OD state might thus be of monotropic character $[19,20]$.

\section{Experimental}

Special grade $\left(\mathrm{CH}_{3}\right)_{3} \mathrm{CCl}$ and $\left(\mathrm{CH}_{3}\right)_{2} \mathrm{CCl}_{2}$ were purchased from Aldrich Chemical and used without additional purification since the measured melting points agreed with those previously reported. Two-component mixed crystals were obtained by cooling samples prepared by mixing pure liquids in the selected proportions at room temperature in high-pressure pans (from Perkin Elmer), made of stainless-steel in order to prevent the samples from reacting with their containers.

Differential scanning calorimetry (DSC) under nitrogen flux was performed in the $160300 \mathrm{~K}$ range using a Perkin Elmer DSC-7 apparatus, and heating and cooling rates of $2 \mathrm{~K} \mathrm{~min}^{-1}$ were used for calorimetric measurements on sample masses of about $25 \mathrm{mg}$.

X-ray powder diffraction studies were performed, as described previously [3 6], by means of a horizontally mounted INEL CPS120 detector (Debye Scherrer geometry, transmission mode, $\lambda \mathrm{CuK} \alpha_{1}=1.5406 \AA$ ) equipped with a liquidnitrogen INEL CRYO950 cryostat and with Helium gas as a heat exchanger. The liquid samples were introduced into $0.3 \mathrm{~mm}$-diameter Lindemann capillaries, which rotate around their axes during data collection.

\section{Results and discussion}

\subsection{Thermal analysis}

For any sample $\left[\left(\mathrm{CH}_{3}\right)_{3} \mathrm{CCl}\right]_{1-X}\left[\left(\mathrm{CH}_{3}\right)_{2} \mathrm{CCl}_{2}\right]_{X}$ of given composition, each series of DSC runs was the following: first, the sample was cooled from room temperature to about $160 \mathrm{~K}$ at $2 \mathrm{~K} \mathrm{~min}^{-1}$ and heated back to room temperature. Then the 
sample was cooled again until the first exothermic peak was recorded, i.e., until the crystallization had occurred. Afterwards, the so-obtained crystalline phase was heated to room temperature.

Three kinds of thermal behaviour were observed as a function of the composition:

- For samples within the $0.11 \leqslant X \leqslant 0.40$ composition range, three phase transitions occur on cooling and, according to X-ray diffraction experiments (see Section 3.2), they were related to liquid $\rightarrow$ FCC, $\mathrm{FCC} \rightarrow \mathrm{R}$, both reverting on heating, and $\mathrm{R} \rightarrow$ LTO phase(s) on further cooling. However effort made to characterize these transitions was unsuccessful because thermal hysteresis was markedly enlarged as the mole fraction increased. The DSC curves of the mixed crystal corresponding to $X=0.30$ are given in Fig. 1a.
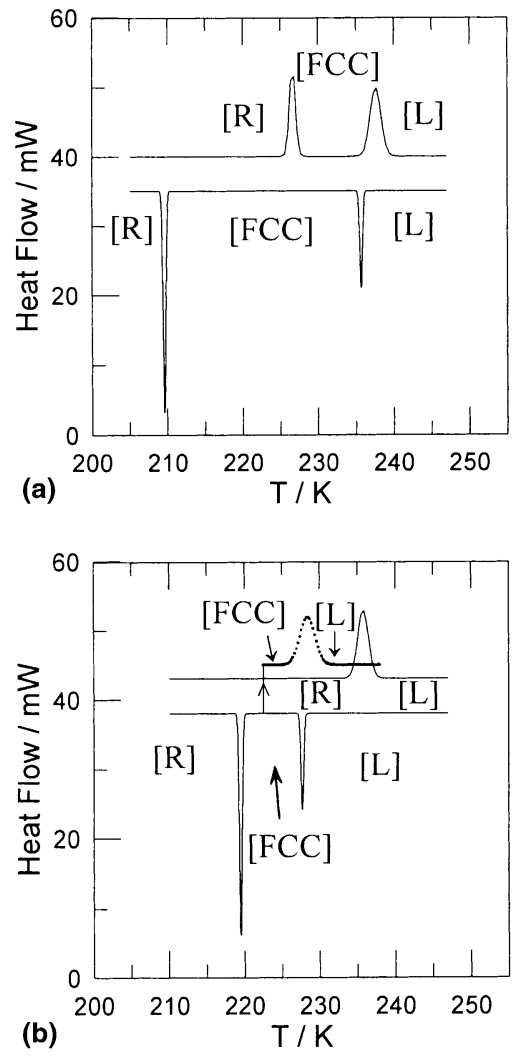

Fig. 1. Heating (a) and cooling (b) DSC curves for $\left[\left(\mathrm{CH}_{3}\right)_{3} \mathrm{CCl}\right]_{1 X}\left[\left(\mathrm{CH}_{3}\right)_{2} \mathrm{CCl}_{2}\right]_{X}$ mixed crystals with mole frac tion $X \quad 0.30(\mathrm{~A})$ and $X \quad 0.70(\mathrm{~B})$.
- For samples within the $0.40<X<0.91$ composition range, the FCC mixed crystals, that form first on cooling from the melt, no longer revert to the $\mathrm{R}$ mixed crystals on heating back and, when these crystals, obtained on further cooling from the FCC phase, are reheated, they melt without having ever reverted to the FCC phase. These results not only point to the metastability of the FCC mixed crystals (their melting temperatures are by several degrees lower than those of the corresponding $\mathrm{R}$ mixed crystals do) but also to the irreversibility of the FCC $\rightarrow \mathrm{R}$ transition, if it were observed on heating, i.e., to its monotropic character. Fig. $1 \mathrm{~b}$ shows the DSC curve of the sample corresponding to $X=0.70$.

- Two dichloropropane-rich samples $(X=0.91$ and $X=0.96$, respectively) were also subjected to DSC following the same experimental procedures. On cooling from the melt the samples behave as those with compositions greater than 0.40 do: the melt crystallizes first into a cubic phase, then the transition to the $\mathrm{R}$ phase occurs on further cooling. It is worth noting that the cubic phase is found to crystallize in either of FCC and SC systems, both being metastable with respect to the $\mathrm{R}$ phase. This is clearly established from crystallographic studies and enthalpy values (see Fig. 2). Moreover, as inferred from the stable and metastable melting phase diagrams shown in Fig. 3, the melting temperatures of the SC phases range between the ones of the corresponding metastable FCC and stable $\mathrm{R}$ phases, and line up (Fig. $3 \mathrm{~b}$ ) with the melting point of the metastable SC phase of pure $\left(\mathrm{CH}_{3}\right)_{2} \mathrm{CCl}_{2}$.

\subsection{Crystallographic study}

The structural changes of the samples were followed by visual examination of short-time acquisition patterns as a function of the temperature, while long-time acquisition patterns were collected at constant temperature, $223.2 \mathrm{~K}$, for which both FCC and R mixed crystals could be obtained.

Rhombohedral mixed crystals. After samples were cooled from room temperature to about 160 $\mathrm{K}$, the temperature was slowly increased up to $223.2 \mathrm{~K}$, at which measurements were carried out. 


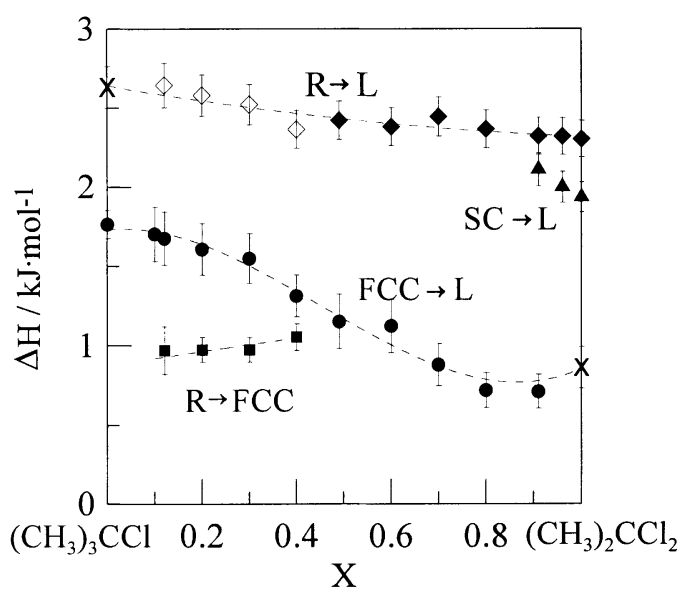

Fig. 2. Experimental (full symbols) enthalpies of melting for the R $(\bullet)$, FCC $(\bullet)$ and SC $(\boldsymbol{\Delta})$ mixed crystals and enthalpy changes for the R to FCC transition ( $\mathbf{\square})$ as a function of the mole fraction. Empty symbols correspond to the values calcu lated from Eq. (6). Crosses correspond to values extrapolated from polynomials described by dotted lines.

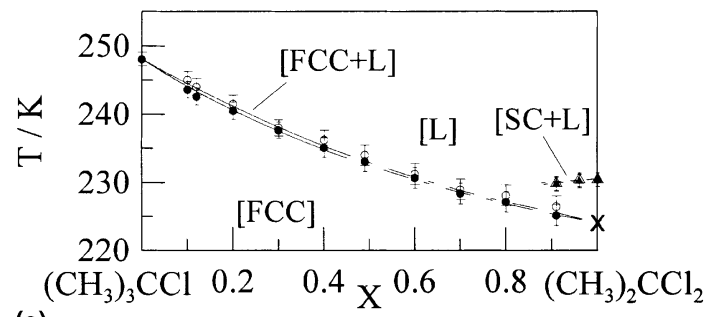

(a)

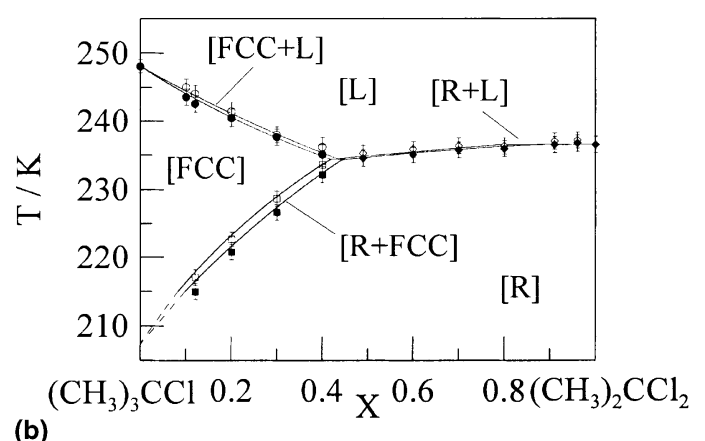

Fig. 3. (a) Stable (continuous line) and metastable (dotted line) parts corresponding to the $[\mathrm{FCC}+\mathrm{L}]$ and $[\mathrm{SC}+\mathrm{L}]$ melting equilibria and (b) stable binary phase diagram of $\left(\mathrm{CH}_{3}\right)_{3} \mathrm{CCl}+\left(\mathrm{CH}_{3}\right)_{2} \mathrm{CCl}_{2}$ calculated from the thermodynamic assessment together with the experimental points. The eutectic point $[\mathrm{FCC}+\mathrm{L}+\mathrm{R}]$ is located at $234.3 \mathrm{~K}$ and $X \quad 0.436$.
Fig. $4 \mathrm{~b}$ shows the lattice parameters of the stable $\mathrm{R}$ mixed crystals as a function of the composition in the $0.40<X \leqslant 1$ range.

FCC mixed crystals. From DSC experiments, the enantiotropic behavior of the FCC mixed crystals was only stated in the $X<0.40$ composition range. However they were found persistent enough in the $0.40<X<1$ range as metastable crystals for their lattice parameter to be determined at $223.2 \mathrm{~K}$ in the whole composition range with the exception of $X=1$, i.e., pure $\left(\mathrm{CH}_{3}\right)_{2} \mathrm{CCl}_{2}$, for which only the SC metastable phase was experimentally available. The continuous change of the FCC lattice parameter value as a function of composition at $223.2 \mathrm{~K}$ is shown in Fig. 4a.

Simple cubic mixed crystals. Although cooling from the melt by means of the DSC technique allowed SC mixed crystals to be obtained for compositions greater than 0.9 , only one sample $(X=0.95)$ was maintained as such while performing X-ray diffraction measurements. The SC lattice
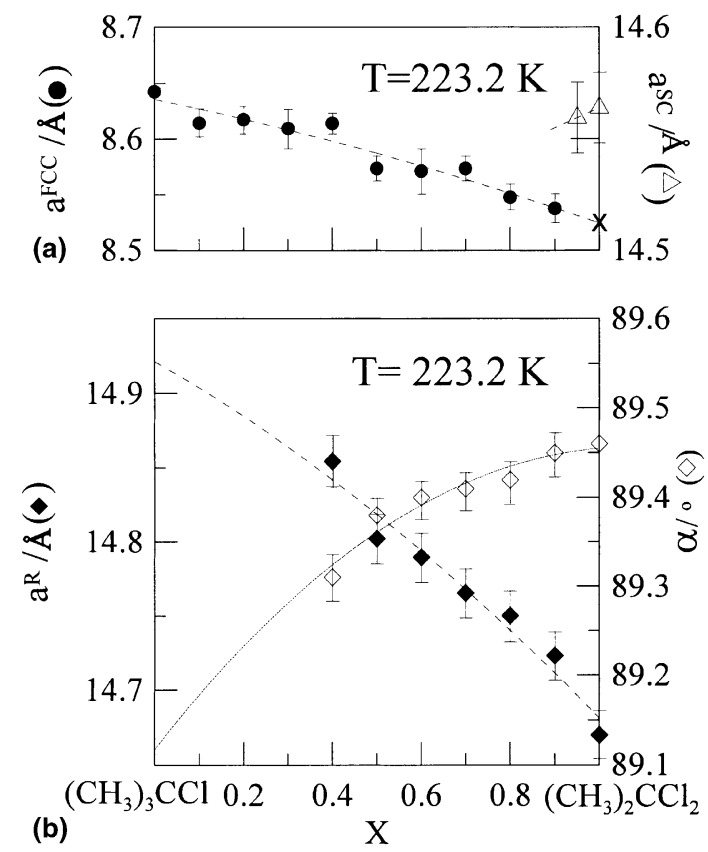

Fig. 4. Lattice parameters $a$ for FCC and SC mixed crystals (a) and $a$ and $\alpha$ for the $\mathrm{R}$ mixed crystals (b) as a function of the mole fraction at $223.2 \mathrm{~K}$. The cross corresponds to the ex trapolated FCC lattice parameter at $X \quad 1$. 
parameter for this sample is plotted in Fig. 4a together with that of pure $\left(\mathrm{CH}_{3}\right)_{2} \mathrm{CCl}_{2}$.

\subsection{Thermodynamic analysis}

The aim of the thermodynamic analysis is to make a fit of the experimental melting phase diagram and to derive the excess properties of the OD phases involved. As a function of temperature $T$, and mole fraction $X$ of component B in a system made of $(1-X)$ mole of $\mathrm{A}$ and $X$ mole of $\mathrm{B}$, the Gibbs energy function of an $\alpha$ phase is given by equation

$$
\begin{aligned}
G^{\alpha}(T, X)= & (1-X) G_{\mathrm{A}}^{*, \alpha}+X G_{\mathrm{B}}^{*, \alpha} \\
& +R T[(1-X) \ln (1-X)+X \ln X] \\
& +G^{\mathrm{E}, \alpha}(T, X),
\end{aligned}
$$

where $G_{\mathrm{i}}^{*, \alpha}, \mathrm{i}=\mathrm{A}$, B stands for the molar Gibbs energy of pure component $\mathrm{i}, R$ is the gas constant and $G^{\mathrm{E}, \alpha}(T, X)$ is the excess Gibbs energy, the deviation from the ideal mixing behavior. The two-phase equilibrium region between the liquid (L) and the $\alpha$ phase will be determined by the intersection between the Gibbs energies of both phases. Assuming that the specific heat does not change noticeably with temperature, it follows that

$$
\begin{aligned}
\Delta_{\alpha}^{\mathrm{L}} G_{\mathrm{i}}^{*}(T) & =G_{\mathrm{i}}^{* \mathrm{~L}}(T)-G_{\mathrm{i}}^{*, \alpha}(T) \\
& \approx \Delta_{\alpha}^{\mathrm{L}} S_{\mathrm{i}}^{*}\left(T_{\mathrm{i}}^{\alpha \rightarrow \mathrm{L}}-T\right),
\end{aligned}
$$

where $\Delta_{\alpha}^{\mathrm{L}} S_{i}^{*}$ is the melting entropy of $\alpha$ phase at $T_{\mathrm{i}}^{\alpha \rightarrow \mathrm{L}}$, the equation

$\Delta_{\alpha}^{\mathrm{L}} G\left(T_{\mathrm{EGC}}, X\right)=0$

provides a curve for equal values of the Gibbs energies of $\alpha$ and $\mathrm{L}$ phases in the $T X$ plane. The equation for this so-called equal- $G$ curve (EGC) is

$$
\begin{aligned}
T_{\mathrm{EGC}}(X)= & -\frac{(1-X) \Delta_{\alpha}^{\mathrm{L}} H_{\mathrm{A}}^{*}+X \Delta_{\alpha}^{\mathrm{L}} H_{\mathrm{B}}^{*}}{(1-X) \Delta_{\alpha}^{\mathrm{L}} S_{\mathrm{A}}^{*}+X \Delta_{\alpha}^{\mathrm{L}} S_{\mathrm{B}}^{*}} \\
& +\frac{\Delta_{\alpha}^{\mathrm{L}} G^{\mathrm{E}}\left(X_{\mathrm{EGC}}\right)}{(1-X) \Delta_{\alpha}^{\mathrm{L}} S_{\mathrm{A}}^{*}+X \Delta_{\alpha}^{\mathrm{L}} S_{\mathrm{B}}^{*}}
\end{aligned}
$$

in which $\Delta_{\alpha}^{\mathrm{L}} H_{\mathrm{i}}^{*}$ is the melting enthalpy for component $\mathrm{i}$ and $\Delta_{\alpha}^{\mathrm{L}} G^{\mathrm{E}}\left(X_{\mathrm{EGC}}\right)=G^{\mathrm{E}, \mathrm{L}}\left(T_{\mathrm{EGC}}, X_{\mathrm{EGC}}\right)-$ $G^{\mathrm{E}, \alpha}\left(T_{\mathrm{EGC}}, X_{\mathrm{EGC}}\right)$. As the $\mathrm{EGC}$ is running between the solidus and liquidus curves of the $[\alpha+\mathrm{L}]$ equilibrium, the estimated position of the EGC curve from the experimental data enables us, as follows from Eq. (4), to determine the excess Gibbs difference $\Delta_{\alpha}^{\mathrm{L}} G_{\mathrm{EGC}}^{\mathrm{E}}(X)$ between $\alpha$ and $\mathrm{L}$ phases. The EGC method (also known as Oonk's method [24]) is applied by means of the WINIFIT [25] or LIQFIT [26] programs. It should be stressed that in the present melting equilibria $([\mathrm{R}+\mathrm{L}],[\mathrm{FCC}+\mathrm{L}]$ and $[\mathrm{SC}+\mathrm{L}])$ the temperature range of the phenomena is rather small, and thus we can express the excess Gibbs energies as a temperature-independent Redlich Kister second-order polynomials

$G^{\mathrm{E}, \alpha}(X)=X(1-X)\left[G_{1}+G_{2}(1-2 X)\right]$.

In the present case the excess Gibbs function of the liquid phase $\left(G_{1}^{\mathrm{L}}=89 \mathrm{~J} \mathrm{~mol}^{-1}\right.$ and $G_{2}^{\mathrm{L}}=122$ $\mathrm{J} \mathrm{mol}^{-1}$ ) is known from vapor pressure measurements [27], thus allowing the excess Gibbs energy of the OD phases to be calculated. With the exception of the $[\mathrm{SC}+\mathrm{L}]$ equilibrium which will be described at the end of this section, the existence of two non-isostructural stable phases in the OD state (FCC and $\mathrm{R}$ for pure compounds $\left(\mathrm{CH}_{3}\right)_{3} \mathrm{CCl}$ and $\left(\mathrm{CH}_{3}\right)_{2} \mathrm{CCl}_{2}$, respectively) entails that a twophase demixing region $[\mathrm{R}+\mathrm{FCC}]$ exists, and that a three-phase equilibrium subsequently occurs, which corresponds in the present case to a eutectic equilibrium (see Fig. 3b). To account for, the melting phase diagram is the result of two interfering melting loops: the first one corresponds to the melting of a complete series of $\mathrm{R}$ mixed crystals, $[\mathrm{R}+\mathrm{L}]$, and the other one to a complete series of FCC mixed crystals, [FCC $+\mathrm{L}]$. This corresponds to the well-known case of crossed isodimorphism [5,6,28]. The metastable ends of the loops are the metastable melting points of the isomorphous metastable phases of the pure compounds, i.e., $T^{\mathrm{R} \rightarrow \mathrm{L}}$ and $T^{\mathrm{FCC} \rightarrow \mathrm{L}}$ for $\left(\mathrm{CH}_{3}\right)_{3} \mathrm{CCl}$ and $\left(\mathrm{CH}_{3}\right)_{2} \mathrm{CCl}_{2}$, respectively. As a consequence, purecomponent melting properties of either stable or metastable phases have to be found by means of either experiments or extrapolation, respectively. As far as temperatures are concerned, $T^{\mathrm{R} \rightarrow \mathrm{L}}$ is obtained by extrapolating the $[\mathrm{R}+\mathrm{L}]$ equilibrium temperatures to $X=0$. The extrapolated value agrees with that obtained in the same way from the two-component systems $\left(\mathrm{CH}_{3}\right)_{3} \mathrm{CCl}+\mathrm{CCl}_{4}$ and 
Table 1

Temperatures and enthalpy changes for pure components

\begin{tabular}{|c|c|c|c|c|}
\hline Component & Transition & $\begin{array}{l}T \\
(\mathrm{~K})\end{array}$ & $\begin{array}{l}\Delta_{\alpha}^{\mathrm{L}} H \\
\left(\mathrm{~kJ} \mathrm{~mol}^{1}\right)\end{array}$ & $\begin{array}{l}\Delta_{\alpha}^{\mathrm{L}} S \\
\left(\mathrm{~J}^{\mathrm{mol}}{ }^{1} \mathrm{~K}^{1}\right)\end{array}$ \\
\hline$\left(\mathrm{CH}_{3}\right)_{3} \mathrm{CCl}$ & $\begin{array}{l}\mathrm{R}^{\mathrm{m}} \rightarrow \mathrm{L} \\
\mathrm{FCC}^{\mathrm{s}} \rightarrow \mathrm{L} \\
\mathrm{SC}^{\mathrm{m}} \rightarrow \mathrm{L}\end{array}$ & $\begin{array}{l}233.5^{\dagger} \\
248.1^{*} \\
223.6^{\ddagger}\end{array}$ & $\begin{array}{l}2.63^{\dagger} \\
1.76^{*} \\
1.93^{\ddagger}\end{array}$ & $\begin{array}{r}11.33^{\dagger} \\
7.11^{*} \\
8.63^{\ddagger}\end{array}$ \\
\hline$\left(\mathrm{CH}_{3}\right)_{2} \mathrm{CCl}_{2}$ & $\begin{array}{l}\mathrm{R}^{\mathrm{s}} \rightarrow \mathrm{L} \\
\mathrm{FCC}^{\mathrm{m}} \rightarrow \mathrm{L} \\
\mathrm{SC}^{\mathrm{m}} \rightarrow \mathrm{L}\end{array}$ & $\begin{array}{l}236.6^{*} \\
224.0^{\dagger} \\
230.4^{*}\end{array}$ & $\begin{array}{l}2.30^{*} \\
0.86^{\dagger} \\
1.93^{*}\end{array}$ & $\begin{array}{l}9.79^{*} \\
3.84^{\dagger} \\
8.38^{*}\end{array}$ \\
\hline
\end{tabular}

The stable and metastable transitions are denoted by superscript 's' or ' $m$ ', respectively. The experimental values are denoted by an asterisk, values extrapolated from experimental ones are denoted by a dagger and values obtained from the thermodynamic assessment are denoted by a double dagger.

$\left(\mathrm{CH}_{3}\right)_{3} \mathrm{CCl}+\left(\mathrm{CH}_{3}\right) \mathrm{CCl}_{3}[5,6]$. Owing to the large extension of the $[\mathrm{FCC}+\mathrm{L}]$ equilibrium, extrapolating $T^{\mathrm{FCC} \rightarrow \mathrm{L}}$ for pure $\left(\mathrm{CH}_{3}\right)_{2} \mathrm{CCl}_{2}$, i.e., $X=1$, can easily be performed.

DSC measurements provide the enthalpy values as a function of the composition for the melting of the R and FCC mixed crystals as well as for the R to FCC transition (Fig. 2). Assuming that the specific heats of the FCC and R mixed crystals are close, enthalpy changes are related by equation

$\Delta H_{\mathrm{R} \rightarrow \mathrm{L}}=\Delta H_{\mathrm{R} \rightarrow \mathrm{FCC}}+\Delta H_{\mathrm{FCC} \rightarrow \mathrm{L}}$

which allows to determine the enthalpy values of the 'virtual' $\mathrm{R}$ mixed crystals with mole fraction lower than $X \approx 0.40$. In addition, extrapolating the melting enthalpy of the R and FCC mixed crystals to $X=0$ and $X=1$, respectively, leads to the melting enthalpy of a 'virtual' $\mathrm{R}$ (metastable) phase of pure $\left(\mathrm{CH}_{3}\right)_{3} \mathrm{CCl}$ and to the one of a 'virtual' FCC (supermetastable) phase of pure $\left(\mathrm{CH}_{3}\right)_{2} \mathrm{CCl}_{2}$. Once again, the extrapolated value at $X=0$ for the melting enthalpy of the 'virtual' $\mathrm{R}$ phase hits the ones previously inferred by applying the same procedure to the $\left(\mathrm{CH}_{3}\right)_{3} \mathrm{CCl}+\mathrm{CCl}_{4}$ and $\left(\mathrm{CH}_{3}\right)_{3} \mathrm{CCl}+\left(\mathrm{CH}_{3}\right) \mathrm{CCl}_{3}$ two-component systems $\left(2.63 \mathrm{~kJ} \mathrm{~mol}^{-1}\right)[5,6]$. As regards the melting enthalpy of the 'virtual' $\mathrm{FCC}$ phase of $\left(\mathrm{CH}_{3}\right)_{2} \mathrm{CCl}_{2}$ the same conclusion can be achieved when compared to the value obtained for the $\left(\mathrm{CH}_{3}\right)_{2} \mathrm{CCl}_{2}+\mathrm{CCl}_{4}$ two-component system $\left(0.86 \mathrm{~kJ} \mathrm{~mol}^{-1}\right)$ [4] for which the FCC mixed crystals were also found to behave monotropically within a large composition range.
As far as the melting of a 'virtual' SC phase of $\left(\mathrm{CH}_{3}\right)_{3} \mathrm{CCl}$ is concerned and because of the very narrow composition domain occupied by the SC mixed crystals in the 2,2-dichloropropane-rich composition side, thermodynamic parameters were obtained by a set of trial calculations of the $[\mathrm{SC}+\mathrm{L}]$ equilibrium. Nevertheless, it should be stressed that no reliable differences between experimental and calculated [SC $+\mathrm{L}]$ loop are found even if the inferred melting enthalpy of the metastable SC phase of the $\left(\mathrm{CH}_{3}\right)_{3} \mathrm{CCl}$ compound is arbitrarily changed within reasonable limits.

The thermodynamic melting properties for stable and metastable phases are compiled in Table 1.

Excess properties of the $\mathrm{R}$ and FCC phases obtained from the described framework are compiled in Tables 1 and 2. The calculated stable melting phase diagram is shown in Fig. $3 b$, while the partially metastable $[\mathrm{FCC}+\mathrm{L}]$ equilibrium is shown in Fig. 3a, both together with the experimental values. Experimental and calculated phase diagrams fairly agree, as shown in Fig. 3 in which

Table 2

Parameters of the Redlich Kister second order polynomials (Eq. (5)) for the excess Gibbs energy of the liquid (L) state and rhombohedral (R) and face centered cubic (FCC) OD mixed crystals

\begin{tabular}{lcl}
\hline Phase & $\begin{array}{l}G_{1} \\
\left(\mathrm{~J} \mathrm{~mol}^{1}\right)\end{array}$ & $\begin{array}{l}G_{2} \\
\left(\mathrm{~J} \mathrm{~mol}^{1}\right)\end{array}$ \\
\hline$[\mathrm{L}]$ & 89.1 & 122.0 \\
{$[\mathrm{R}]$} & 94.9 & 183.4 \\
{$[\mathrm{FCC}]$} & 242.8 & 161.8 \\
\hline
\end{tabular}


the maximum deviation for both solidus and liquidus curves, $1.2 \mathrm{~K}$, is within the experimental error limits. In addition, it should be emphasized that the calculated $[\mathrm{R}+\mathrm{FCC}]$ two-phase equilibrium matches up to the experimental one, despite the excess Gibbs energy functions (Eq. (5)) are assumed to be temperature-independent.

\section{Concluding remarks}

The experimental results of Fig. 4a were used to extrapolate the lattice parameter of a virtual FCC phase of $\left(\mathrm{CH}_{3}\right)_{2} \mathrm{CCl}_{2}$. It came $a=8.525 \AA$, which corresponds to $V^{\mathrm{FCC}} / Z=154.9 \AA^{3}$, close to the experimentally available values for the metastable SC phase $\left(V^{\mathrm{SC}} / Z=154.5 \AA^{3}\right)$ and for the stable $\mathrm{R}$ phase $\left(V^{\mathrm{R}} / Z=150.3 \AA^{3}\right)$, all at $223.2 \mathrm{~K}$ [22]. The small difference between the values of the FCC and SC metastable phases would be a clue for orientational disorder to be similar in either of both phases. In addition, the three $V / Z$ values follow the density rule according to which the metastability degree increases as the density the packing of decreases [29], thus phase $\mathrm{R}$ were the most stable phase, SC the metastable one and, finally, the experimentally non-available 'virtual' FCC phase would be a supermetastable phase of $\left(\mathrm{CH}_{3}\right)_{2}$ $\mathrm{CCl}_{2}$.

Excess Gibbs energies were obtained from the thermodynamic assessment. Fig. 5 shows the Gibbs energies of the OD phases scaled to the liquid state at $234.3 \mathrm{~K}$, the temperature of the eutectic equilibrium. Regardless of the magnitude of the Gibbs energy of the SC phase for 2-methyl2-chloropropane-rich compositions for which the assumed SC melting enthalpy change can substantially influence, the 2,2-dichloropropane-rich composition side clearly evidences two facts: (i) the small difference between the SC and FCC Gibbs energies, and (ii) the supermetastable to metastable change of the SC phase for compositions greater than $X \approx 0.92$. This coherently goes along with the thermal and X-ray diffraction measurements in this composition region.

Lastly, it is worth noting that the $\left(\mathrm{CH}_{3}\right)_{3} \mathrm{CCl}+$ $\left(\mathrm{CH}_{3}\right)_{2} \mathrm{CCl}_{2}$ two-component system is another

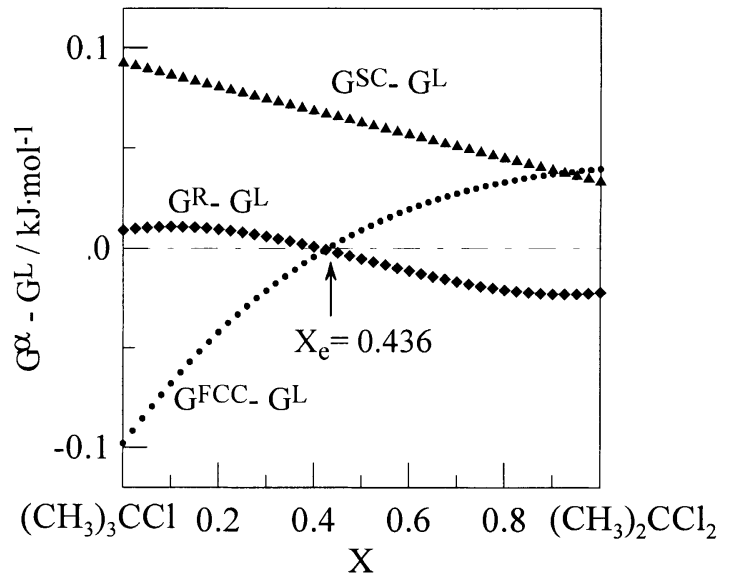

Fig. 5. Gibbs energies of the OD phases scaled to the liquid state at $234.3 \mathrm{~K}$ for the $\mathrm{R}(\bullet), \mathrm{FCC}(\bullet)$ and SC $(\boldsymbol{\Delta})$ mixed crystals. At this temperature, $G^{\mathrm{R}}, G^{\mathrm{FCC}}$ and $G^{\mathrm{L}}$ are equal at the eutectic point $X \quad 0.436$, where EGC temperature is the same for both $[\mathrm{R}+\mathrm{L}]$ and $[\mathrm{FCC}+\mathrm{L}]$ equilibria.

case for which crossed isodimorphism is experimentally available. As far as the $\left(\mathrm{CH}_{3}\right)_{4-n} \mathrm{CCl}_{n}$ series is concerned, the existence of isodimorphism relationships between stable and metastable phases allows additional metastable experimentally nonavailable phases to be inferred, as it is in this Letter for the 'virtual' rhombohedral metastable phase of $\left(\mathrm{CH}_{3}\right)_{3} \mathrm{CCl}$ as well as for the 'virtual' supermetastable FCC phase of $\left(\mathrm{CH}_{3}\right)_{2} \mathrm{CCl}_{2}$.

\section{Acknowledgements}

This work was supported by grant PB98-0923 from the Spanish DGE. The authors would like to thank Prof. Dr. R. Céolin for helpful discussions and valuable comments.

\section{References}

[1] N.G. Parsonage, L.A.K. Stavely, Disorder in Crystals, Clarendon, Oxford, 1978.

[2] R. Rey, L.C. Pardo, E. Llanta, K. Ando, D.O. López, J.Ll. Tamarit, M. Barrio, J. Chem. Phys. 112 (2000) 7505.

[3] L.C. Pardo, M. Barrio, J.Ll. Tamarit, D.O. López, J. Salud, P. Negrier, D. Mondieig, Chem. Phys. Lett. 308 (1999) 204. 
[4] L.C. Pardo, M. Barrio, J.Ll. Tamarit, D.O. López, J. Salud, P. Negrier, D. Mondieig, Chem. Phys. Lett. 321 (2000) 438.

[5] L.C. Pardo, M. Barrio, J.Ll. Tamarit, D.O. López, J. Salud, P. Negrier, D. Mondieig, Phys. Chem. Chem. Phys. 3 (2001) 2644

[6] L.C. Pardo, M. Barrio, J.Ll. Tamarit, P. Negrier, D.O. López, J. Salud, D. Mondieig, J. Phys. Chem. B. 105 (2001) 10326.

[7] R. Rudman, B. Post, Mol. Cryst. 5 (1968) 95.

[8] R. Rudman, B. Post, Science 154 (1966) 1009.

[9] R. Rudman, J. Mol. Struct. 485486 (1999) 281.

[10] K. Kobashi, M. Oguni, J. Phys. Chem.. B. 103 (1999) 7687.

[11] L. Silver, R. Rudman, J. Phys. Chem. 74 (1970) 3134.

[12] M.N. Akimov, O.F. Bezrukov, O.V. Chikunov, A.V. Struts, J. Chem. Phys. 95 (1991) 22.

[13] A.V. Struts, O.F. Bezrukov, Chem. Phys. Lett. 232 (1995) 181.

[14] A.V. Struts, Phys. Rev. B. 51 (1995) 5673.

[15] Y. Koga, J.A. Morrison, J. Chem. Phys. 62 (1975) 3359

[16] J.A. Morrison, E.L. Richards, M. Sakon, Mol. Cryst. Liq. Cryst. 43 (1977) 59.

[17] T. Hasebe, S. Ohtani, J. Chem. Soc. Faraday Trans. I 84 (1988) 187.

[18] W. Ostwald, Z. Phys. Chem. 22 (1897) 289.

[19] R. Céolin, V. Agafonov, D. Louer, A. Dzyabchenko, S. Toscani, J.M. Cense, J. Solid State Chem. 122 (1996) 186.
[20] O. Leemann, in: Molekularphysik, vol. 1, Engelmann, Leipzig, 1888, p. 193;

O. Lehmann, in: Die Kristallanalyse, Engelmann, Leipzig, 1888 , p. 23.

[21] J.Ll. Tamarit, D.O. López, X. Alcobé, M. Barrio, J. Salud, L.C. Pardo, Chem. Mater. 12 (2000) 555.

[22] P. Negrier, L.C. Pardo, J. Salud, J.Ll. Tamarit, M. Barrio, D.O. López, A. Wurflinger, D. Mondieig, Chem. Mater. (in press).

[23] R. Rudman, Mol. Cryst. Liq. Cryst. 6 (1970) 427.

[24] H.A.J. Oonk, Phase Theory: The Thermodynamics of Heterogeneous Equilibria, Elsevier Science Publishers, Amsterdam, 1981.

[25] D. Daranas, R. López, D.O. López, Winifit 2.0: A Windows Computer Program for the Thermodynamic Assesment of T X Phase Diagrams using the C.I.C (Crossed Isopolymorphism Concept), Polythecnic Univer sity of Catalonia, Barcelona, 2000.

[26] M.H.G. Jacob, H.A.J. Oonk, Liqfit. A computer pro gram for the Thermocynamic Assesment of T X Liquidus or Solidus data, Utrecht University, The Netherlands, 1990.

[27] L.C. Pardo, Ph.D. Thesis, Polytechnic University of Catalonia, Barcelona (in preparation).

[28] J.S. van Duijneveldt, N.B. Chanh, H.A.J. Oonk, Calphad 13 (1989) 83.

[29] A.I. Kitaigorodsky, Mixed Crystals, Springer Verlag, Ber lin, 1984. 